\title{
OPTIMISATION OF A POROUS ELECTROOSMOTIC PUMP, USED IN THERMAL COOLING SYSTEM OF POWER ELECTRONICS.
}

\author{
Y.Berrouche \\ Laboratoire génie électrique \\ Grenoble, G2Elab \\ Institut national polytechnique \\ de Grenoble INPG, France \\ y.berrouche@g2elab.inpg.fr
}

\author{
Y. Avenas \\ Laboratoire génie électrique \\ Grenoble, G2Elab \\ Institut national polytechnique \\ de Grenoble INPG, France \\ y.avenas@g2elab.inpg.fr
}

\author{
C. Schaeffer \\ Laboratoire génie électrique \\ Grenoble, G2Elab \\ Institut national polytechnique \\ de Grenoble INPG, France \\ c.schaffeffer@g2elab.inpg.fr
}

\author{
P.Wang \\ Center of micro-fluidics and medical \\ diagnostics, Notre dame university, USA \\ pwang@nd.edu
}

\author{
H-C.Chang \\ Center of micro-fluidics and medical \\ diagnostics, Notre dame university, USA \\ hcchang@nd.edu
}

\begin{abstract}
The liquid cooling of electronic components is generally implemented by a mechanical pump, which requires a minimal maintenance to ensure the reliability of the device. To solve this problem, it is proposed to replace the mechanical pump by a static one, for example an electro-osmotic (EO) pump. In this paper, firstly we present the theory of the electro-osmosis phenomena, and a model of a porous EO pump. Then an optimization of a porous EO pump made of sintered silica is presented. It was found that for any porous EO pump the optimum operating point of the pump is determined by controlling the diameter of the effective pore radius of the porous silica and the Debye length. Using deionised (DI) water as pumping liquid, the EO pump generates $13.6 \mathrm{ml} / \mathrm{min}$ and 2 $\mathrm{kPa}$ at $150 \mathrm{~V}$ applied voltage. The power consumed by the pump is less than $0.4 \mathrm{~W}$. The EO pump works without any bubbles in the hydraulic circuit. This design can be used to cool $47 \mathrm{~W}$ of power generated by the power components with a forced convection without evaporation and $270 \mathrm{~W}$ with evaporation.
\end{abstract}

\section{INTRODUCTION}

The integration of the power electronic components has become more and more common. Hence the cooling of these components became more difficult because of the high heat density generated in small area. To make the cooling easy, the heat power must be evacuated farther from the electronic components. This procedure can be made by the forced convection which can be with or without evaporation. In fig.1 the heat power generated by the electronic components is absorbed by the cooling fluid with the help of the heat exchanger. When the fluid arrives to the heat sink the heat power will be liberated. To ensure the motion of the fluid, a pump is required. In general a mechanical pump is used. The mechanical pump has a problem of reliability, it generates a noise and its cost is expensive.

To cool a high heat density, the heat exchanger must have a high heat transfer coefficient, for which we need to increase the contact between the wall surface of the heat exchanger and the cooling fluid. Hence a microchannel heat exchanger can be used. The problem of this kind of heat exchangers is that they need a very high pressure, which is not easy to be generated by the classical mechanical pump. For that purpose, this pump must be replaced by a high pressure mechanical pump (HPMP), which is very expensive, big and very noisy. Another way to solve this problem is the use of an electro-kinetic (EK) pump. One of the most popular EK pumps is the electroosmotic (EO) pump, which is very cheap compared to the other EK pumps [1], generates high pressure in small volume and is very easy to be manufactured. 


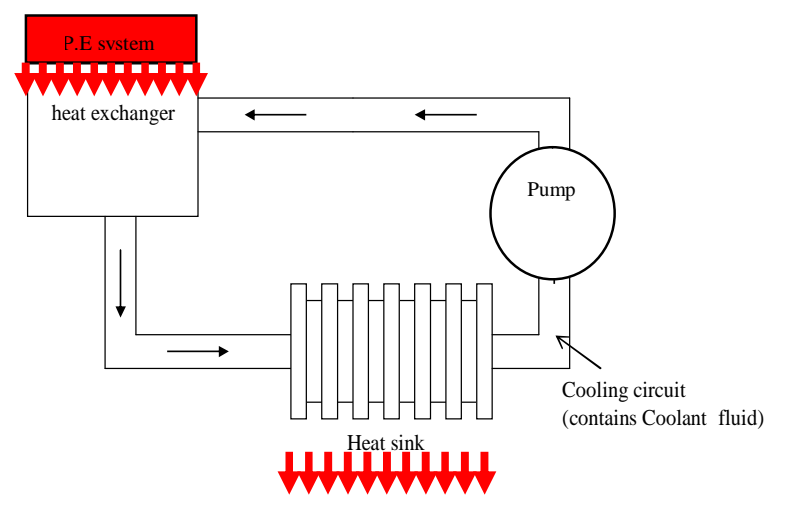

Fig. 1: The forced convection used in the thermal cooling of the power components.

But the EO pumps have a problem of very low thermodynamic efficiency like all the EK pumps, generation of bubbles in the electrodes due to the electrolysis, and high dependency on the $\mathrm{pH}$ of the working fluid. Our work consists to replace the mechanical pump used in the forced convection to cool the power electronic components by a porous EO pump.

In this paper an energetic study of the forced convection will be presented in order to determine the heat power that can be evacuated using an EO pump in the forced convection for two cases: with and without evaporation. Next the theory of electro-osmosis pumping in a capillary is recalled. Third a study and modeling of the Electro-osmosis in a porous medium is given. In order to increase the thermodynamic efficiency, an optimization of a porous EO pump will be presented next. This optimization is the focus of this paper. To verify this optimization and to study the possibility to use the porous EO pump in the electronic components cooling, a test setup and experimental results of our prototype are presented. In this prototype, solutions are proposed in order to solve the major problems of the EO pumps (generation of bubbles in the hydraulic circuit, stability ...).

\section{NOMENCLATURE}

A Cross-sectional area of the porous silica disk $\left(\mathrm{m}^{2}\right)$.

C Specific heat capacity $(\mathrm{J} / \mathrm{kg} / \mathrm{K})$.

$\mathrm{D}_{\mathrm{h}} \quad$ hydraulic diameter $(\mathrm{m})$.

E Tangential electric field (V/m).

$\mathrm{H}$ The high of the micro heat exchanger (m).

I Current (A).

In The $\mathrm{n}$ order modified Bessel function of the first kind.

$\mathrm{K} \quad$ Ion mobility $\left(4 \times 10^{-8} \mathrm{~m}^{2} / \mathrm{V} / \mathrm{s}\right)$.

Le The length of the micro heat exchanger $(\mathrm{m})$.

$\mathrm{L}_{v} \quad$ Latent heat of the working fluid $(\mathrm{J} / \mathrm{kg})$.

$\mathrm{Nu} \quad$ Nusselt number.

$\mathrm{P}_{\mathrm{E}} \quad$ Heat power generated by the electronic component (W).

$\Delta \mathrm{P} \quad$ Pressure drop $(\mathrm{Pa})$.

Q Flow rate ( $\mathrm{ml} / \mathrm{min})$.

Re Reynolds number.

$\mathrm{T} \quad$ Temperature of the liquid (K).

V Applied voltage (V).

W The width of the micro heat exchanger (m).
$\Delta \mathrm{T} \quad$ Difference of the temperature between the input and the output of the heat exchanger $(\mathrm{K})$.

capillary radius $(\mathrm{m})$.

$a_{e f f} * \quad$ Normalized pore radius $(\mathrm{a} / \lambda)$.

e Electron charge $\left(1.6 \times 10^{-19} \mathrm{C}\right)$.

$e_{e} \quad$ The width of the micro canal of the micro heat exchanger $(\mathrm{m})$.

g The gravity $\left(9.8 \mathrm{~m} / \mathrm{s}^{2}\right)$

$\mathrm{h}$ heat exchange coefficient $\left(\mathrm{W} / \mathrm{m}^{2} / \mathrm{K}\right)$.

$\mathrm{k}_{\mathrm{B}} \quad$ Boltzmann constant $\left(1.38 \times 10^{-23} \mathrm{~m}^{2} \mathrm{~kg} / \mathrm{s}^{2} / \mathrm{K}\right)$.

$\mathrm{k}_{\mathrm{l}} \quad$ Thermal conductivity of the liquid $(\mathrm{W} / \mathrm{m} / \mathrm{K})$.

1 Length of the porous silica disk (m).

$1_{c} \quad$ Capillary length.

$\mathrm{n} \quad$ Counter ions concentration of bulk solution (M).

$\mathrm{r} \quad$ Radial coordinate $(\mathrm{m})$.

$r^{*} \quad$ Normalized radial coordinate $(r / \lambda)$.

$\mathrm{Z} \quad$ valance number of the counter ions.

$\varepsilon \quad$ Permittivity of liquid $(\mathrm{C} / \mathrm{V} / \mathrm{m})$.

$\eta \quad$ Thermodynamic efficiency.

$\lambda \quad$ Debye length (m).

$\psi \quad$ Inner potential at a point distance $r / \lambda$ from the wall $(\mathrm{V})$.

$\mu \quad$ Viscosity (Pa.s).

$\sigma\left(r^{*}\right) \quad$ Conductivity at a point distance $r / \lambda$ from the wall $(\mathrm{S} / \mathrm{m})$.

$\sigma \quad$ Conductivity of the bulk (S/m).

$\rho \quad$ Density of the working fluid $\left(\mathrm{kg} / \mathrm{m}^{3}\right)$.

$\rho_{\mathrm{E}} \quad$ Electrical charge density $\left(\mathrm{C} / \mathrm{m}^{3}\right)$.

$\zeta \quad$ Zeta potential (V).

$\tau$ Tortuosity.

$\Psi \quad$ Porosity.

Subscript

a ambient

c capillary

com component

$e \quad$ exchanger

eff effective

$m$ maximum

$o \quad$ operating

op optimum

$T$ Total

$w \quad$ wall exchange

\section{ENERGETIC STUDY OF THE FORCED CONVECTION}

The principle of the forced convection

The principle of the forced convection is presented in fig. 1: the heat power generated by the electronic component is absorbed by the cooling fluid with the help of the heat exchanger. When the fluid arrives to the heat sink, the heat power will be dissipated in the ambient area. In case of forced convection without evaporation, thermal losses induce an increase of the fluid temperature between the inlet and the outlet of the heat exchanger. In the case of forced convection with evaporation, the liquid becomes a vapor in the heat exchanger (evaporator) and it takes the liquid form in the heat sink (condenser). In each case a minimum flow rate of the liquid is required to ensure the cooling of power electronic components. This flow rate can be given by an energetic study.

\section{Evacuated heat power calculation}

Let's consider a micro heat exchanger presented in the fig. 2 . This end has a length $\mathrm{L}_{\mathrm{e}}=1 \mathrm{~cm}$, a width $\mathrm{W}=1 \mathrm{~cm}$ and a height $\mathrm{H}=0.5 \mathrm{~cm}$. Each microchannel in this heat exchanger has a section $\mathrm{e}_{\mathrm{e}} \times \mathrm{e}_{\mathrm{e}}$. The distance between two microchannels is $\mathrm{e}_{\mathrm{e}}$. The EO pump generates an operating flow rate $Q_{o}$ and a 
pressure drop $\Delta \mathrm{P}_{\mathrm{o}}$. To ensure the best function of the electronic component, its temperature must be less than $\mathrm{T}_{\text {com, } \mathrm{m}}=125^{\circ} \mathrm{C}$.

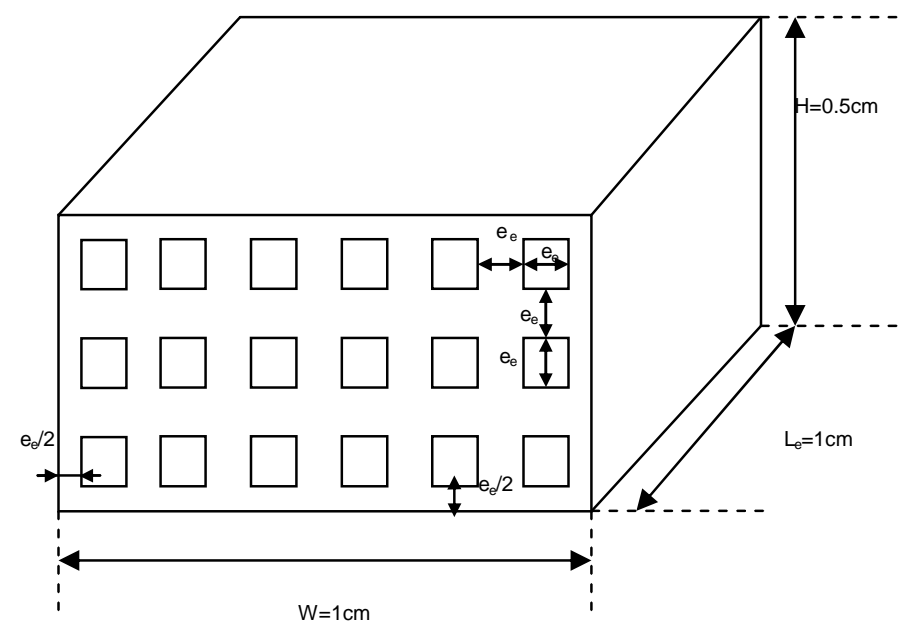

Fig. 2: The micro heat exchanger schematic.

If we assume that the electronic component has a temperature $\mathrm{T}_{\text {com }}$ equal to the wall temperature $\mathrm{T}_{\mathrm{w}}$ (the temperature drop induced by heat conduction in the heat exchanger is neglected), the maximum transmitted power can be written in case of forced convection without evaporation as [2]:

$$
P_{E, m}=\frac{T_{c o m, m}-T_{a}}{\frac{1}{h S_{e}}+\frac{1}{\rho \cdot Q_{o} \cdot C}}
$$

where $T_{a}, h, S, \rho, C, Q_{o}$, and $P_{E, m}$ are the fluid temperature at the inlet of the heat exchanger, the heat transfer coefficient, the heat exchange surface, the fluid density, the specific heat capacity of the fluid, the flow rate and the maximum power generated by the electronic component respectively.

The pressure drop in the heat exchanger is given as [2]:

$$
\Delta P=\frac{64}{\operatorname{Re}} \cdot \frac{1}{2} \cdot \rho \cdot u^{2} \cdot \frac{L_{e}}{D_{h}}
$$

where $R e, u$ and $D_{h}$ are Reynolds number, the fluid velocity and the hydraulic diameter which is $e_{e}$ in our case.

This pressure must be equal to the operation one, hence

$$
\Delta P_{o}=\frac{128 \cdot \mu \cdot L_{e} \cdot Q_{o}}{W \cdot H \cdot e_{e}^{2}}
$$

For a pump, the relation between $\mathrm{P}_{\mathrm{o}}$ and $\mathrm{Q}_{\mathrm{o}}$ is determined by the $\mathrm{Q}(\mathrm{P})$ characteristic. Hence the next equation gives the dimensional constraints for the heat exchanger to be used with this pump.

$$
e_{e}=\sqrt{\frac{128 \cdot \mu \cdot L_{e} \cdot Q_{o}}{W \cdot H \cdot \Delta P_{o}}}
$$

The heat transfer surface is given by:

$$
S_{e}=\frac{W \cdot H \cdot L_{e}}{e_{e}}
$$

The heat exchange coefficient is given as a function of Nusselt number as

$$
h=\frac{k_{l} \cdot N u}{e_{e}}
$$

where $k_{1}$ is the thermal conductivity of the liquid and $\mathrm{Nu}$ is the Nusselt number.

Replacing (4), (5) and (6) in (1), we get

$$
P_{E, m}=\frac{\left(T_{c o m, m}-T_{a}\right)}{\frac{128 \cdot \mu \cdot Q_{o}}{W^{2} \cdot H^{2} \cdot k_{l} \cdot N u \cdot \Delta P_{o}}+\frac{1}{\rho \cdot Q_{o} \cdot C}}
$$

In such an application, $e_{e}$ is very small (tens of microns) hence the Reynolds number is very small, therefore the flow is laminar that gives a Nusselt number equal to 3.66 [2]. The heat power depends therefore only on $\mathrm{Q}_{\mathrm{o}}$ and $\Delta \mathrm{P}_{\mathrm{o}}$ of the pump.

In forced convection with evaporation, there are three separate parts in the heat exchanger: one section where the fluid is only in a liquid state (inlet of the heat exchanger), an other section where there are both liquid and vapor and finally a vapor section. For best functioning, the latter should be as small as possible because of the bad heat transfer coefficient between a wall and a gas. Generally the first section is small. Hence, if we assume that the heat absorption is only made by vapor change, the liquid flow rate at the inlet and the heat generated by the components are related by:

$$
P_{E}=\rho \cdot Q \cdot L_{v}
$$

where $L_{v}$ is the evaporation latent heat of the working fluid.

Therefore, if the heat transfer coefficient by evaporation is sufficient, the maximum electronic component losses can be approximated to:

$$
P_{E, m}=\rho \cdot Q_{o} \cdot L_{v}
$$

For example in order to cool with water a $100 \mathrm{~W}$ of power generated by the component, the pump must generate at least $29 \mathrm{~mL} / \mathrm{min}$ and $5 \mathrm{~mL} / \mathrm{min}$ for forced convection without and with evaporation respectively.

It can be seen that the flow rate required in the forced convection with evaporation is too less than the one in the forced convection without evaporation. Knowing that the flow rate generated by the EK pumps is very small [3], hence the use of the EO pump is better in the forced convection with 
evaporation, but in this case the use of deionized (DI) water or any other pure liquid is essential in order to avoid the precipitation of salts in the heat exchanger because of the evaporation. The experimental tests of a realized pump with DI water will be therefore presented in the experimental section.

\section{THEORY OF EO PUMPING}

The basis of EO pumps is the formation and manipulation of electric double layers (fig .3). If we consider that a liquid is in contact with a wall (electrical insulator as a ceramic), the wall will be charged positively or negatively, and forms the charged surface, which will attract the ions of the opposite charge in the liquid, the so-called counter-ions. Hence, an area will exist where the concentration of counter-ions is larger than that of the co-ions. This phenomenon leads to the formation of an electric double layer or Debye layer. The remaining of the liquid stays neutral which is called the bulk.

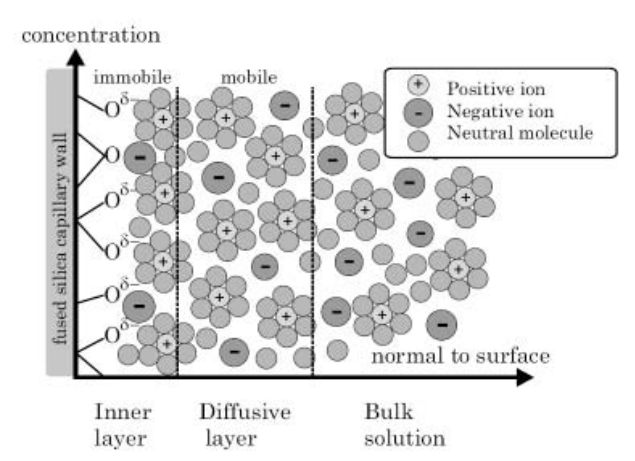

Fig. 3: Structure of electric double layer (EDL).

The Debye layer is divided into two layers, the inner one (Stern layer), which is immobile due to strong electrical forces, and the outer one (the diffusive layer), which contains free charges, this layer has a length called Debye length $\lambda$ which can be given as [4]:

$$
\lambda=\sqrt{\frac{\varepsilon k_{B} T}{2 e^{2} \cdot z^{2} \cdot n}}
$$

where $\varepsilon, \mathrm{n}, \mathrm{k}_{\mathrm{B}}, \mathrm{T}$, e and $\mathrm{z}$ are the dielectric permittivity of the liquid, the counter ions concentration of bulk solution, Boltzmann number, the temperature of the liquid, the electron charge and the valance number of the counter ions respectively.

For an aqueous solution of asymmetric electrolyte at $25^{\circ} \mathrm{C}$, the Debye length becomes [5]

$$
\lambda=\frac{9.61 \times 10^{-9}}{\sqrt{z^{2} \cdot n}}
$$

With $\lambda$ in meters and $n$ in Mol.m ${ }^{-3}$
Here we see that the Debye length can be controlled by adjusting the counter ions concentration, which can be controlled by changing the conductivity of the liquid.

The electrical potential between these layers is called zeta potential $\zeta$ which highly depends on the $\mathrm{pH}$ of the working fluid. The diffusive layer may be easily affected by an external tangential electric field. When that happens, ions in this layer suffer a Coulombic force, and move toward the electrode of opposite polarity. This creates motion of the fluid near the wall and transfers momentum via viscous forces into the bulk (fig. 4).

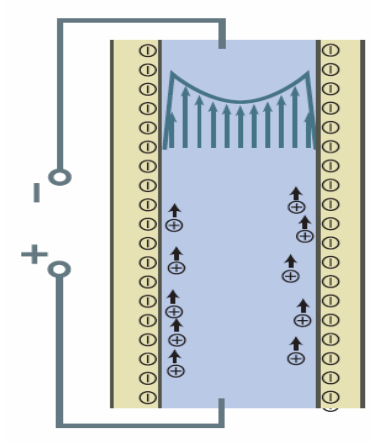

Fig. 4: The EO pumping in a capillary.

The Navier-Stokes equation for an incompressible liquid can be given as

$$
\rho\left(\frac{\partial U}{\partial t}+(U . \nabla) \cdot U\right)=-\nabla P+\mu \nabla^{2} U+\rho_{V} \cdot g+\rho_{E} \cdot E
$$

where $\rho, U, P, \mu, g, \rho_{E}, E$ are the density of the liquid, the velocity vector, the pressure, the fluid viscosity, the gravity, the electrical charge density in the Debye layer and the electrical field respectively.

In a capillary of radius $a$, Rice and Whitehead [6] derived the velocity profile $\mathrm{u}(\mathrm{r})$ under a tangential electrical field ' $E$ ', assuming that the pressure gradient is constant, the gravity force is neglected and the fluid is incompressible.

$$
u(r)=\frac{-a^{2}}{4 \mu} \frac{\Delta P}{l_{c}}\left(1-\frac{r^{2}}{a^{2}}\right)-\frac{\varepsilon \xi \cdot E}{\mu}\left(1-\frac{\psi(r)}{\xi}\right)
$$

In Eq.13, $\mu, \zeta, \Delta \mathrm{P}$ and $\mathrm{l}_{\mathrm{c}}$ are the viscosity of the working fluid, the zeta potential, the pressure drop and the length of capillary respectively. $\psi(\mathrm{r})$ is the potential in the capillary due to electric double layer called inner potential. The velocity profile in a capillary of a radius $a$ for different pressure drops has been drawn in fig. 5, where the pressure drop influences the velocity profile, which stays corresponding to the EO pumping in fig .4. 


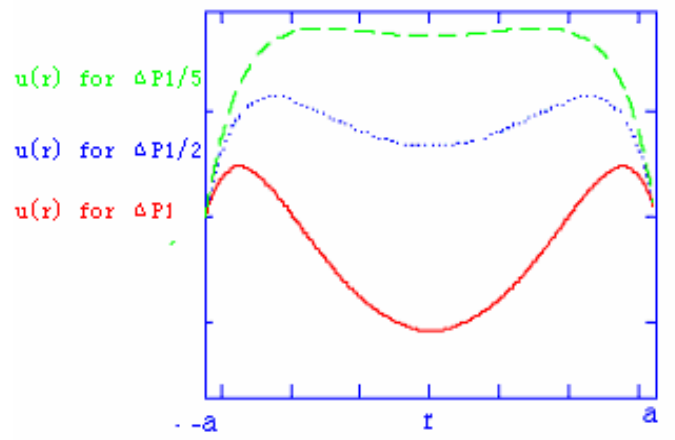

Fig. 5: The velocity profile $u(r)$ in a capillary of radius a for different values of the pressure drop.

In order to get a closed-form analytical solution of the profile of inner potential across the capillary, the Debye-Huckle approximation can be used [5]. This assumption gives:

$$
\psi(r)=\xi . \frac{I_{0}\left(\frac{r}{\lambda}\right)}{I_{0}\left(\frac{a}{\lambda}\right)}
$$

where $I_{0}$ is the zero-order modified Bessel function of the first kind.

The variation of the normalized inner potential profile $\frac{\psi(r)}{\xi}$ in a capillary of radius $a$ for various values of the Debye length is shown in fig. 6 . It can be seen that the inner potential profile depends on the Debye length and hence on the conductivity of the liquid.

The integration of Eq.13 in a capillary on a section $\pi a^{2}$, gives the formulation of flow rate as

$$
Q_{c}=\frac{-\pi a 4}{8 \mu l_{c}} \Delta P-\frac{\pi a^{2} \xi \varepsilon E}{\mu} \int_{0}^{a}\left(1-\frac{I_{0}\left(\frac{r}{\lambda}\right)}{I_{0}\left(\frac{a}{\lambda}\right)}\right) \cdot \frac{2 r}{a^{2}} d r
$$

\section{Use of the porous structure}

The very small value of Debye length $(\mathrm{nm})$ gives a very low range of the flow rate $(\mu 1 / \mathrm{min})[7,8]$. To increase the hydraulic power, we have to increase the surface contact between wall and the liquid, hence a porous structure can be used. To create this structure it is possible to use a monolithic silica matrix, which can be made from sol-gel. The mechanical resistance of the monolithic silica matrix is low, hence it can be used only for a capillary EO pump [1], or for decreasing the porosity of the sintered silica. The monolithic silica matrix can be easily prepared by referring to the procedures of [9-11]. Other authors like Santiago [12] and Brask [4] have used sintered borosilicate disks that contain $80.60 \%$ silica $\left(\mathrm{SiO}_{2}\right), 12.60 \%$ boric oxide $\left(\mathrm{B}_{2} \mathrm{O}_{3}\right)$, and $4.20 \%$ sodium oxide $\left(\mathrm{Na}_{2} \mathrm{O}\right)$. These samples are fabricated by the company ROBU (Germany). A third way to get a porous structure is the packed of the silica particles, this method is presented in [13].

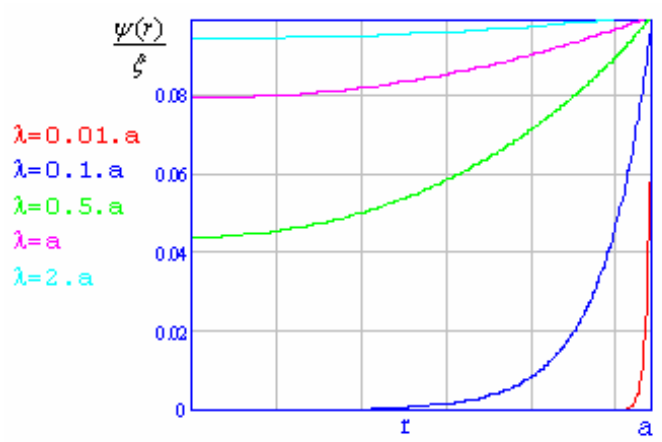

Fig. 6: The variation of the normalized inner potential profile for different values of the Debye length.

\section{Model of a porous structure}

The theoretical study of the Electro-Osmosis in a porous structure is very complicated due to complex geometry of the sintered silica. To simplify the study of a porous disk Zeng et al. [3] extended the maximum pressure $\Delta \mathrm{P}_{\mathrm{m}}$ and the maximum flow rate $\mathrm{Q}_{\mathrm{m}}$ for a porous EO pump as follows

$$
\begin{gathered}
Q_{m}=\frac{\Psi \cdot A \cdot \xi \varepsilon V}{\mu \cdot l \cdot \tau} \cdot\left(1-\frac{2}{a_{e f f} / \lambda} \frac{I_{1}\left(a_{e f f} / \lambda\right)}{I_{0}\left(a_{e f f} / \lambda\right)}\right) \\
\Delta P_{m}=\frac{8 \xi \varepsilon V}{a_{e f f}^{2}} \cdot\left(1-\frac{2}{a_{e f f} / \lambda} \frac{I_{1}\left(a_{e f f} / \lambda\right)}{I_{0}\left(a_{e f f} / \lambda\right)}\right)
\end{gathered}
$$

In Eq. 16 and 17, $\Psi, \tau$, aeff and $V$ are the porosity, the tortuosity $\left(\left(\frac{l_{c}}{l}\right)^{2}\right)$, the effective pore radius of porous silica disk and the applied voltage respectively. I0 and I1 are the zero and the first order modified Bessel function of first kind.

\section{OPTIMIZATION OF A POROUS EO PUMP}

In order to increase the thermodynamic efficiency of the EO pumping, a study of an analytical formula of the optimum thermodynamic efficiency will be calculated in this paragraph. 
The thermodynamic efficiency of an EK pump represents the hydraulic power generated over the total electrical power consumed by the pump which can then be given as

$$
\eta(\Delta P)=\left|\frac{Q(\Delta P) \cdot \Delta P}{V I_{T}(\Delta P)}\right|
$$

In Eq.18, $\mathrm{Q}, \Delta \mathrm{P}, \mathrm{V}$ and $\mathrm{I}_{\mathrm{T}}$ are the operating flow rate, the operating pressure drop, the applied voltage and the total consumed current in EO pump respectively, assuming that the losses due to electrochemical reactions are neglected.

Because the pump is a generator of the hydraulic power, the flow rate can be given as a function of pressure as follow, assuming that this function is linear [1]:

$$
Q(\Delta P)=Q_{m}\left(1-\frac{\Delta P}{\Delta P_{m}}\right)
$$

Lets consider a porous silica disk, which has a section $A$, a length $l$, a porosity $\Psi$, a tortuosity $\tau$ and effective pore radius $a_{\text {eff }}$ , this disk therefore can be considered as a plural parallel capillary pumps of radius $a_{\text {eff }}$.

In Eq.18, the total current is divided into three parts: the electro-convection current $\mathrm{I}_{\text {con }}$, the electro-migration current $\mathrm{I}_{\text {meg }}$ and the diffusion current. The last one is neglected compared to other two [2 \& 17]. $I_{\text {con }}, I_{\text {meg }}$ can be given as

$$
\begin{gathered}
I_{c o n}=\iint_{S} \rho_{E}(r) \cdot u(r) d s \\
I_{m e g}=\iint_{S} \sigma(r) \cdot E \cdot d s
\end{gathered}
$$

$\mathrm{S}, \sigma(r)$, and $\rho_{E}(r)$ are the cross-section, the electrical conductivity and the free density charge in Debye layer respectively, that they can be written as [5]

$$
\begin{gathered}
\rho_{E}(r)=-\frac{\varepsilon}{\lambda^{2}} \psi(r) \\
\sigma(r)=K \cdot n \cdot \cosh \left(\frac{z \cdot e \cdot \psi(r)}{k_{B} \cdot T}\right)
\end{gathered}
$$

$K$ is the ion mobility.

In a capillary of a radius $a_{\text {eff }}$, using (13) equations (20) and (21) become

$$
\begin{gathered}
I_{c o n}=2 \pi\left(\frac{\lambda^{2} \cdot \varepsilon a_{e f f}^{* 2}}{4 \mu} \frac{P^{2}}{l_{c}} \int_{0}^{a_{e j}^{*}}\left(1-\frac{r^{* 2}}{a_{e f f} *^{2}}\right) \psi\left(r^{*}\right) r^{*} d r^{*}-\frac{\varepsilon^{2} \xi V^{a_{e f l}^{*}}}{\mu l} \int_{0}^{*}\left(1-\frac{\psi\left(r^{*}\right)}{\xi}\right) \psi\left(r^{*}\right) r^{*} d r^{*}\right. \\
I_{m e g}=-\int_{0}^{a_{e f f}^{*}} \lambda^{2} \frac{V}{l} \cdot \sigma\left(r^{*}\right) r^{*} d r^{*}
\end{gathered}
$$

with $a_{e f f} *=\frac{a_{e f f}}{\lambda}, r^{*}=\frac{r}{\lambda}$ and $V=\frac{-E}{l}$ and are the normalized pore radius, the normalized radial coordinate in the capillary and the applied voltage respectively.

Hence the current can be written as

with

$$
I=\Delta P \cdot \Gamma_{1}-V \cdot \Gamma_{2}
$$

$$
\begin{gathered}
\Gamma_{1}=\frac{2 \cdot \pi \cdot \lambda^{2} \cdot \varepsilon \cdot a_{e f f} *^{2}}{4 \mu l_{c}} \int_{0}^{a_{e f f}{ }^{*}}\left(1-\frac{r^{* 2}}{a_{e f f} *^{2}}\right) \psi\left(r^{*}\right) \cdot r^{*} d r^{*} \\
\Gamma_{2}=\frac{2 \cdot \pi \cdot \varepsilon^{2} \xi}{l_{c} \cdot \mu} \int_{0}^{a_{e f f}^{*}}\left(1-\frac{\psi\left(r^{*}\right)}{\xi}\right) \cdot \psi\left(r^{*}\right) r^{*} d r^{*}+\int_{0}^{a_{e f f^{*}}} \frac{2 \cdot \pi \cdot \lambda^{2}}{l_{c}} \sigma\left(r^{*}\right) r^{*} d r^{*}
\end{gathered}
$$

Therefore the total current in a porous structure is the resultant current of the currents in plural parallel capillary pumps. The current $\mathrm{I}_{\mathrm{T}}$ in the Equ. 18 becomes then

$$
\begin{aligned}
I_{T} & =\Delta P \cdot \Xi_{1}-V \cdot \Xi_{2} \\
\text { With } \Xi_{1,2} & =\frac{\Psi \cdot A}{\sqrt{\tau} \cdot \pi \cdot a_{\text {eff }}^{2}} \cdot \Gamma_{1,2}
\end{aligned}
$$

Optimum thermodynamic efficiency

Putting $\Delta P^{*}=\frac{\Delta P}{\Delta P_{m}}$, the Eq.18 will be

$$
\begin{gathered}
\eta\left(\Delta P^{*}\right)=\left|\frac{\alpha \Delta P^{*}\left(1-\Delta P^{*}\right)}{\Delta P^{*}-\beta}\right| \\
\text { with } \beta=\frac{V . \Xi_{2}}{\Delta P_{m} \Xi_{1}} \text { and } \alpha=\frac{Q_{m}}{V \Xi_{1}}
\end{gathered}
$$

$\eta$ is maximum for a value of $\Delta \mathrm{P}^{*}$ :

$$
\Delta P_{o p}^{*}=\beta\left(1-\sqrt{1-\frac{1}{\beta}}\right)
$$

The second development of Taylor serial of $\Delta P_{o p}{ }^{*}$ gives

$$
\Delta P_{o p} * \approx \frac{1}{2}+\frac{1}{8 \beta}
$$

Therefore

$$
\eta_{o p}=\alpha \frac{\frac{1}{4}-\frac{1}{(8 \beta)^{2}}}{\beta-\frac{1}{2}-\frac{1}{8 \beta}}
$$

$\beta$ is higher than 1 , that gives

$$
\eta_{o p} \approx \frac{\alpha}{4 \beta}
$$


Finally the optimum thermodynamic efficiency can be approximated as

$\eta_{p p}\left(a_{e f f^{*}}^{*}\right) \approx \frac{\left[\int_{0}^{a_{e f f}^{*}}\left(1-\frac{I_{0}\left(r^{*}\right)}{I_{0}\left(a_{e f f}\right)}\right) \cdot \frac{2 r^{*}}{a_{e f f}^{*}} d r^{*}\right]^{2}}{\sqrt{\tau} \cdot\left[\left(\int_{0}^{a_{e f f}^{*}}\left(1-\frac{I_{0}\left(r^{*}\right)}{I_{0}\left(a_{e f f}^{*}\right)}\right) \cdot \frac{I_{0}\left(r^{*}\right)}{I_{0}\left(a_{e f f}^{*}\right)} \cdot r^{*} d r^{*}+\int_{0}^{a_{e f}^{*}} \frac{k_{B} \cdot K \cdot T \cdot \mu}{z \cdot e \varepsilon \xi^{2}} \cosh \frac{z e \xi \xi}{k_{B} \cdot T} \frac{I_{0}\left(r^{*}\right)}{I_{0}\left(a_{e f f}^{*}\right)}\right) r^{*} d r^{*}\right]}$

\section{Discussion}

We see that the optimum thermodynamic efficiency depends only on the temperature, the Zeta potential $(\mathrm{pH})$, the viscosity, the permittivity, the valance number, the tortuosity and principally of the effective normalized pore radius.

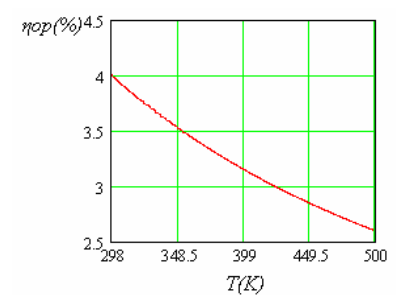

(a) $\quad \mu=10^{-3} \mathrm{~Pa} . \mathrm{s}, \varepsilon_{\mathrm{r}}=78.8, \zeta=100 \mathrm{mV}, \mathrm{z}=1, \mathrm{a}^{*}=4$.

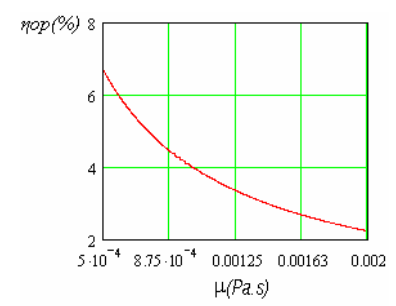

(b). $\mathrm{T}=25^{\circ} \mathrm{C}, \varepsilon_{\mathrm{q}}=78.8, \zeta=100 \mathrm{mV}, \mathrm{z}=1, \mathrm{a}^{*}=4$.

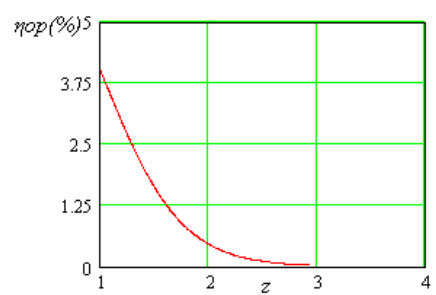

(c) $\mathrm{T}=25^{\circ} \mathrm{C}, \mu=10^{3} \mathrm{~Pa} . \mathrm{s}, \varepsilon_{\mathrm{r}}=78.8, \zeta=100 \mathrm{mV}, \mathrm{a}^{*}=4$.

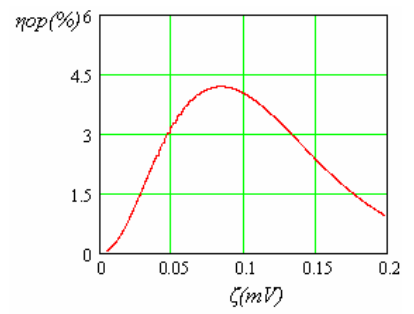

(d) $\mathrm{T}=25^{\circ} \mathrm{C}, \mu=10^{-3} \mathrm{~Pa} . \mathrm{s}, \varepsilon_{\mathrm{q}}=78.8, \mathrm{z}=1, \mathrm{a}^{*}=4$.

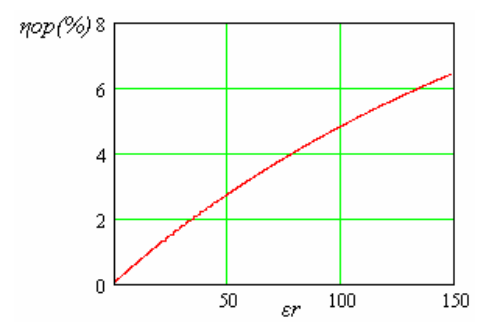

(e) $\mathrm{T}=25^{\circ} \mathrm{C}, \mu=10^{-3} \mathrm{~Pa} . \mathrm{s}, \mathrm{z}=1, \zeta=100 \mathrm{mV}, \mathrm{a}^{*}=4$.

Fig. 7: Influence of the (a) the temperature, (b) the viscosity, (c) the valance number, (d) the Zeta potential and (e) the relative permittivity $n$ the optimum thermodynamic efficiency. For an effective normelized pore radius 4.

From fig. 7, it is clear that the optimum thermodynamic efficiency decreases when either the temperature or the viscosity or the valance number increases. However it is maximum for zeta potential equal to $95 \mathrm{mV}$ for $a_{e f f}{ }^{*}=4$. The tortuosity has not big effect on the optimum thermodynamic efficiency because of its small variety interval (1-1.5). In practice these parameters are not changed, hence the only way to control the optimum thermodynamic efficiency is by adjusting the effective normalized pore radius $a_{\text {eff }}$.

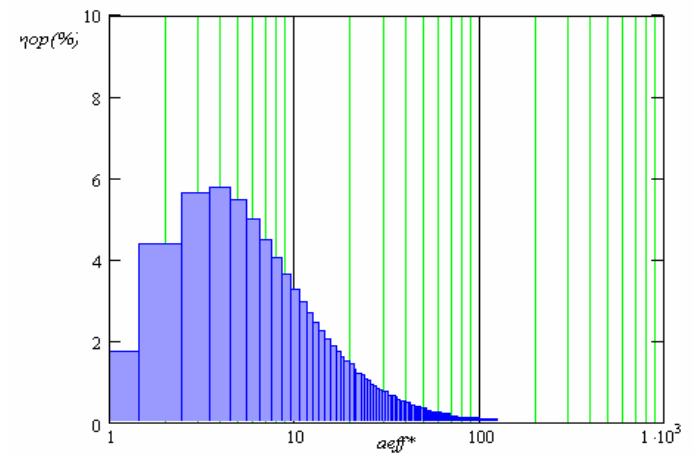

Fig. 8: The variation of the optimum efficiency in function of the normalized pore radius aeff*.

From fig.8, it is seen that the optimum thermodynamic efficiency is maximum when the normalized effective pore radius is 4 .

\section{Conclusion on the optimum thermodynamic efficiency}

Hence for any EO porous pump cross-section (A), and length (1), the optimum thermodynamic efficiency is given for an effective pore radius of the porous structure about 4 times the Debye length, which can be controlled by adjusting the conductivity of pumping liquid or by changing the effective pore radius.

Rocking from the effective the pore radius to the real radius 
In practice what we need to know is the real radius of the particles that construct the porous area. To rock from the effective pore radius to the real radius of particles, a model has been given [15]. This model gives effective pore radius about 0.16 times the real radius. Our model has been applied for different designs found in literature (Tab.I).

\begin{tabular}{|c|l|l|}
\hline & $\begin{array}{l}\text { D.S. Reichmuth } \\
\text { pump }\end{array}$ & $\begin{array}{l}\text { Santiago } \\
\text { pump }\end{array}$ \\
\hline Effective pore radius $^{\mathbf{a}}(\boldsymbol{\mu m})$ & 0.53 & 0.55 \\
\hline Real radius of the particles $^{\mathbf{a}}(\boldsymbol{\mu m})$ & 3.5 & {$[1-5]$} \\
\hline Real radius of the particles $^{\mathbf{m}}(\boldsymbol{\mu m})$ & 3.43 & 3.5 \\
\hline
\end{tabular}

$\left({ }^{\mathrm{a}}\right)$ given by the author, $\left({ }^{\mathrm{m}}\right)$ given by the model.

Tab 1. TEST OF THE MODEL FOR TOW PUMPS GIVEN IN THE LITERATURE .

In order to verify the optimum thermodynamic calculation, an experiment setup is presented in the next paragraph.

\section{FABRICATION AND CHARACTERIZATION}

\section{The design}

The design and characterizations of the porous EO pump has been presented in [15]. In fig. 9 the EO pump design can be divided into three big parts, the electrode chamber anode $\left(\mathrm{A}_{1}\right)$, the electrode chamber cathode $\left(\mathrm{A}_{2}\right)$ and the disk holder $(\mathrm{B})$. All of these parts are made of Plexiglas, which has the advantage of transparency and it's easy to be machined. Each electrode chamber contains electrode made of carbon (D), the contact between carbon and the external wire is assured by a gilded copper connector. The use of carbon avoids the corrosion of the electrode when the pump works. Next to the carbon electrode there is a mesh (E) made of Plexiglas which holds ion exchange membrane (IEM) (F). The aim of the IEM is to keep a stable $\mathrm{pH}$ of working fluid [4], and to avoid the existence of gas bubbles (in the hydraulic circuit) generated by electrolysis in the electrode chambers. These IEMs have been bought from the company Fumatech@ (Germany). The disk holder is used to hold a sintered pure silica disk (C). This disk has been bought from ROBU. It has a section $\mathrm{A}=\pi .(2.5 \mathrm{~cm})^{2}$ and a length $=3.5 \mathrm{~mm}$, with a porosity $\Psi=35 \%$, a tortuosity $1<\tau<1.5$ and an effective pore radius $0.75 \mu \mathrm{m}$.

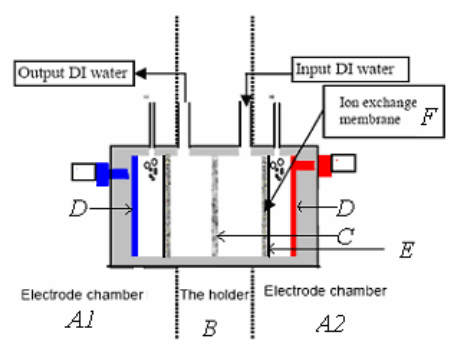

Fig. 9: The Schematic design of the porous EO pump
The volume of the first prototype is $80 \times 80 \times 60 \mathrm{~mm}$ (fig. 10). This volume can be reduced keeping the same performance. In deed in (16), $\frac{A}{l}$ is constant, therefore if the cross-section and the length of the porous disk are reduced with the same factor, the maximum flow rate is kept the same.

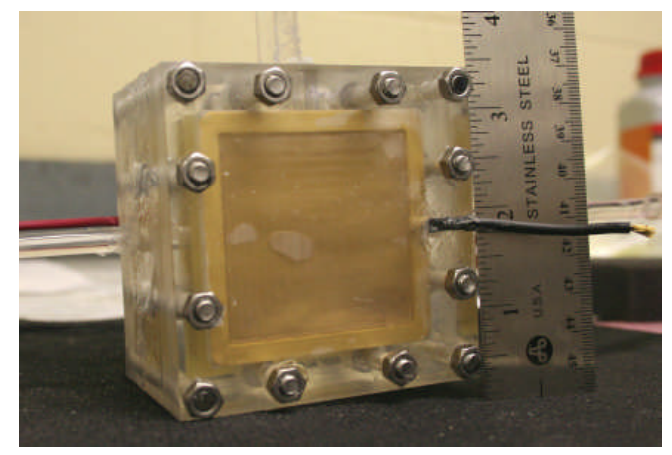

Fig. 10: The design of the porous EO pump

\section{Measurement setup}

The characterization of the pump consists of determining the maximum pressure drop, the maximum flow rate and the power consumption. The measurement setup is presented in fig.11.

In the maximum pressure drop measurement setup, the outlet of the EO pump is closed by a pressure sensor, which forbids the fluid motion, hence the measured pressure is the maximum pressure drop generated by the pump. In the maximum flow rate measurement setup, the input and output of the pump are put at the same height, hence they have the same pressure, the measured flow rate is therefore the maximum flow rate of the pump which can be measured by weighting the pumped liquid by a balance which is connected to a computer.

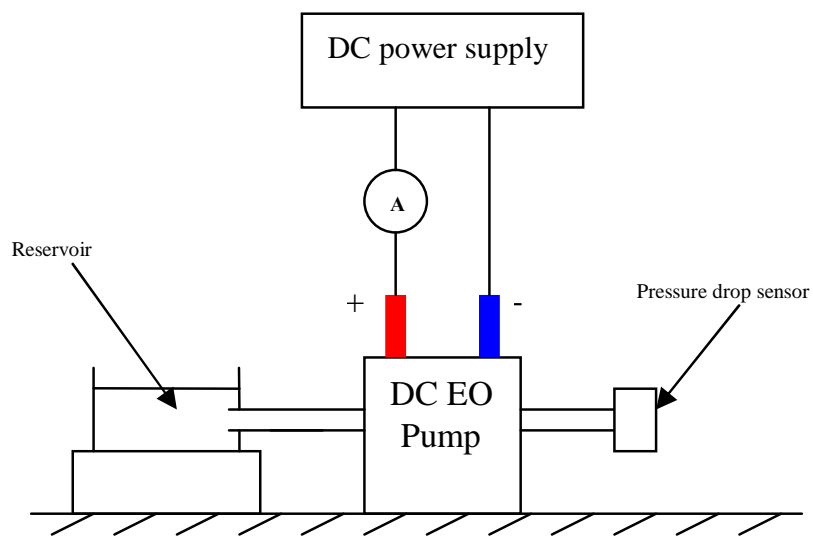

(a) Maximum pressure drop measurement. 


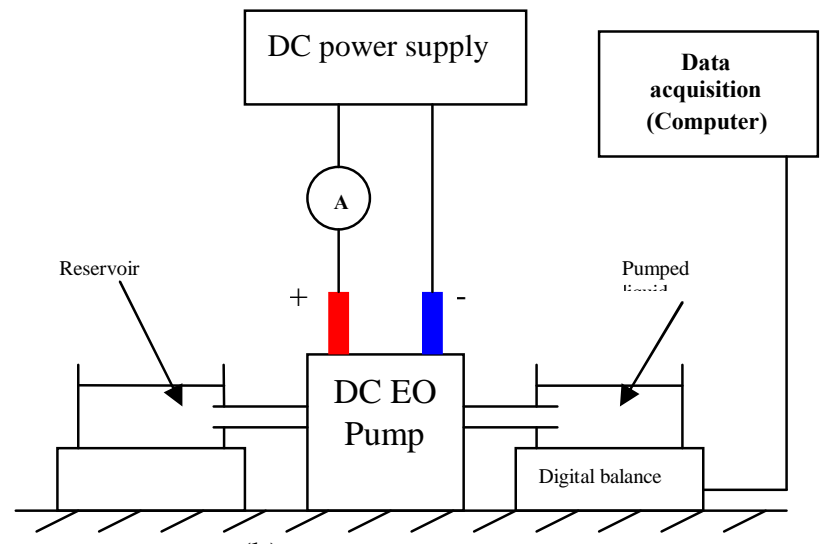

(b) Maximum flow rate measurement.

Fig. 11: Measurement setup.

The software used to control the balance is WinCT Data Communication from A\&D company. In booth setup the power consumption is given by measuring the applied voltage and current consumed by the pump. In order to study the possibility of use of EO pump in the thermal cooling and to verify the optimum thermodynamic efficiency model, the EO has been tested with DI water and with an electrolyte respectively.

\section{Operation of the pump with DI water}

As it was presented in the introduction, the pump will be used with a micro heat exchanger in order to cool high heat density in small area. The flow rate generated by EK pumps is low, therefore EO pump will be tested with forced convection with evaporation, where a low flow rate is required comparing the forced convection without evaporation. In this case, the use of a pure liquid is required in order to avoid precipitations in the heat exchanger. Hence in order to study the possibility of using the EO pump in forced convection with evaporation, it must be tested with DI water (a pure liquid).

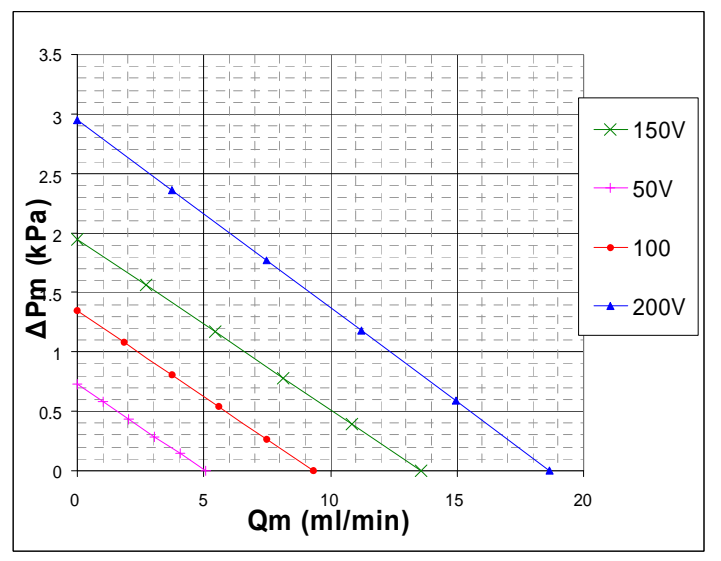

Fig. 12: Performance curves for the EO pump showing max flow rate versus max pumping pressure for different operating voltages. The pumping liquid ids the DI water.
The $\mathrm{Q}_{\mathrm{m}}-\Delta \mathrm{P}_{\mathrm{m}}$ diagram of the EO pump with DI water is presented in the fig.12. The EO pump can generate until $13.6 \mathrm{ml} / \mathrm{min}$ and $1.9 \mathrm{kPa}$ at $150 \mathrm{~V}$ and $18 \mathrm{ml} / \mathrm{min}$ at $200 \mathrm{~V}$. The electric power used by the pump at $150 \mathrm{~V}$ is only $217.5 \mathrm{~mW}$ and it gives a hydraulic power of $0.47 \mathrm{~mW}$, hence the thermodynamic efficiency is $0.2 \%$. In this case it is possible to cool 47W (from Eq.7) without evaporation and 271.4W (from Eq.9) with evaporation. Hence in order to cool 100W with forced convection with evaporation the $\mathrm{EO}$ consumes only $0.02 \mathrm{~W}$, and $1 \mathrm{~W}$ without evaporation. In each case the power consumption of the EO pump stays very low compared to the heat power that must be evacuated. The pump works without any noise compared to mechanical pumps and without any bubbles in the hydraulic circuit.

\section{Operation of the pump with an electrolyte.}

This test targets the verification of the model of the optimum thermodynamic efficiency. The optimum thermodynamic efficiency can be approximated to the maximum thermodynamic efficiency which is given in Eq.38.

$$
\eta_{\text {exp }}=\frac{\frac{Q_{m}}{2} \cdot \frac{\Delta P_{m}}{2}}{V \cdot \frac{I_{m}}{2}}
$$

In order to change the normalized effective pore radius, the Debye length has been changed by using various values of conductivity of $\mathrm{NaCl}$ electrolyte. The tested silica disk has an effective pore radius of about $0.75 \mu \mathrm{m}$ (datasheet), Tab.II represents the normalized pore radius and the Debye length for different values of conductivity of this disk.

\begin{tabular}{|c|c|c|c|c|c|c|}
\hline Conductivity $\boldsymbol{\mu S} / \mathbf{m}$ & 5 & 25 & 110 & 300 & 734 & 1000 \\
\hline$\lambda(\boldsymbol{\mu m})$ & 0.373 & 0.167 & 0.079 & 0.048 & 0.031 & 0.026 \\
\hline $\boldsymbol{a}_{\text {eff }}^{*}$ & 2.0 & 4.5 & 9.4 & 15.6 & 24.4 & 28.5 \\
\hline
\end{tabular}

Tab 2. THE NORMALIZED PORE RADIUS FOR VARIOUS CONDUCTIVITIES, THE EFFECTIVE PORE RADIUS IS $0.75 \mu \mathrm{m}$.

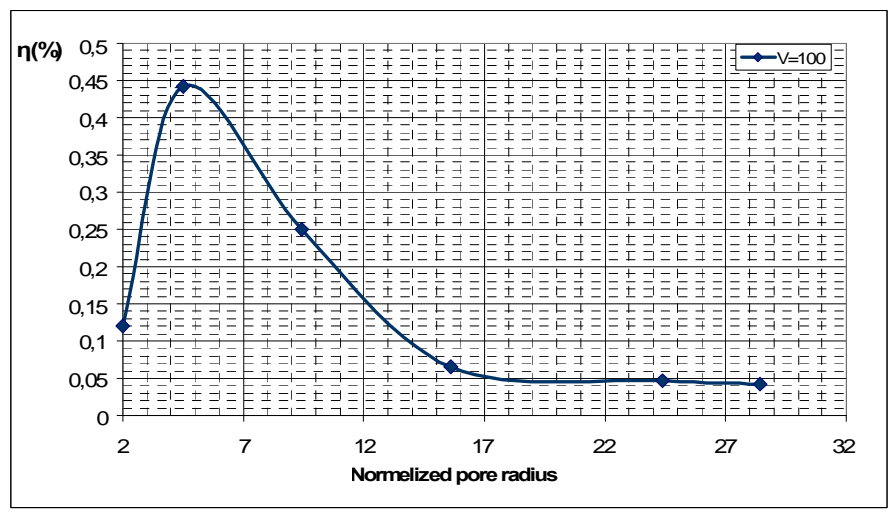

Fig. 13: The variation of the thermodynamic efficiency for various normalized pore radius. 
The variation of the thermodynamic efficiency for various normalized pore radius is given fig.13. It can be clearly seen that the optimum thermodynamic efficiency is given for a normalized pore radius of 4.5 which corresponds to a Debye length $0.17 \mu \mathrm{m}$ and to a conductivity of $25 \mu \mathrm{S} / \mathrm{m}$. This result hence verifies the optimization of the thermodynamic efficiency model given above.

\section{CONCLUSION}

In this paper, we have presented an analytical expression for the flow rate, pressure, and thermodynamic efficiency of a porous EO pump. After describing a model of a porous EO pump, the pump is optimized. It is illustrated that for any volume of the EO pump, and for any applied voltage, the optimum thermodynamic efficiency is given for an effective pore radius of the porous structure 4 times higher than the Debye length. Which has been verified by the experiment. Using DI water as a pumping liquid the pump generates 13.6 $\mathrm{ml} / \mathrm{min}$ and $1.9 \mathrm{kPa}$ at $150 \mathrm{~V}$ and $18.7 \mathrm{ml} / \mathrm{min}$ and $2.95 \mathrm{kPa}$ at $200 \mathrm{~V}$, the electrical power consumption of the pump is less than $0.4 \mathrm{~W}$. The thermodynamic efficiency is low $(0.2 \%)$ but the power consumption of the EO pump stays very low compared to the heat power generated by the electronic components. The EO pump works without any noise and no bubbles are observed in the hydraulic circuit. Future work targets the experimental test of the pump with a heat cooling exchanger with and without evaporation, and the study of integration of the pump in the whole system.

\section{REFERENCES}

[1] Wang, P., Chen, Z., Chang, H. C., 2005, “A new electroosmotic pump based on silica monoliths," Sensors and actuators B 133, pp. 500-509.

[2] Meyzenc, L., 1998, "Etude des mocro échangeurs intégrés pour le refroidissemnt des semi conducteurs de puissance", $\mathrm{PhD}$ thesise, National polytechnic institut of grenoble, Chap2 and 3.

[3] Laser, J. D., Santiago, J. G., 2004, "A review of micropumps," Journal of micromechanics and microengineering, S0960-1317(04)06813-5, pp. 35-64.

[4] Brask, A., 2005, "Electroosmotic micropumps," Phd thesis Department of Micro and Nanotechnology Technical University of Denmark, pp. 2-40.

[5] Probstein, R. F., 1994, "Physicochemical Hydrodynamics," $2^{\text {nd }}$ edition, Wiley, New York, pp. 165208.
[] Rice, C. L., Whitehead, R., 1965, "Electrokinetic flow in a narrow cylindrical capillary," J. Phys. Chem., 694017.

[7] Goodson, K., Santiago, J., Kenny, T., Jiang, L., Zeng, S., Koo, J. M., Zhang, L., Yao, S., Wang, E., 2002, "Electroosmotic microchannel cooling system for microprocessors. electronics-cooling," IEEE Trans., 25, pp. 347-355.

[] Takamura, Y., Oki, A., 2003, "low voltage electroosmosis pump for stand-alone microfluidics devices," Electrophoressis , 24, pp. 185-192.

[9] Chen, Z., Hobo, T., 2001, “Chemically 1-prolinamidemodified monolithic silica column for enantiomeric separation of dansyl amino acids and hydroxy acids by capillary electrochromatography and high performance liquid chromatography,", Electrophoresis, 22, pp. 33393346 .

[10] Chen, Z., Hobo, T., 2001,'Chemically 1phenylalaninamide-modified monolithic silica column prepared by a sol-gel process for enantioseparation of dansyl amino acids by ligand exchangecapillary electrochromatography," Anal. Chem. 73, pp. 3348-3357.

[11] Leinweber, F. C., Lubda, D., Cabrera, K., Tallarek, U., 2002, "Characterization of silica-based monoliths with bimodal pore size distribution", Anal. Chem. 74, pp. 247022477.

[12] Zeng, S., Chen, C., Mikkelsen, J. C., Santiago, J. G., 2001, "Fabrication and characterization of electrokinetic micro pumps," Sens. Actuators B, Chem. 79 pp. 107-114.

[14] Zenga, S., Chena, C. H., Santiago, J. G., Chen, J. R., Zareb, R. N., Trippc, J.A., Svec, F., Fréchet, J.M.J. "Electroosmotic flow pumps with polymer frits", Sensors and Actuators B , 82, pp. 209-212.

[15] Berrouche, Y., Avenas, Y., Schaeffer, C., Wang, P., Chang H. C., 2007 "Design of a porous electroosmotic pump, used in power electronics cooling," IEEE, Industry Applications Society, September 23-27, 2007 New Orleans, Louisiana, USA.

[16] Jiang, L., Mikkelsen, J., Koo, J. M., Huber, D., Yao, S., Zhang, L., Zhou, P., Maveety, J.G., Prasher, R., Santiago „J.C., Kenny, T.W., Goodson, K.E., 2002, "Closed-Loop Electroosmotic Microchannel Cooling System for VLSI Circuits". IEEE Transactions On Components And Packaging Technologies, 25, no. 3. 
[17] Bruus, H., 2005 "Theoretical microfluidics," Lecture notes $2^{\text {nd }}$ edition, Department of Micro and Nanotechnology Technical University of Denmark, pp. 115-149.
[18] Grieser F. 1985, "Thermal and radiation controle of the electrical double layer properties of silica and glass,". Radiat phys and chem. 22, No 1-2 pp 43-48. 